\title{
VALER (VÁ LER?): FORMAÇÃO DE TRABALHADORES SOB A IDEOLOGIA DO MERCADO NA UNIVERSIDADE CORPORATIVA DA VALE
}

\author{
VALER:WORKER QUALIFICATION UNDER THE MARKET IDEOLOGY AT THE VALE CORPORATE \\ UNIVERSITY
}

Giovane Saionara Ramos ${ }^{1}$

Aparecida de Fátima Tiradentes dos Santos ${ }^{2}$

Resumo Este artigo tem como objetivo discutir a concepção de educação dos projetos de formação profissional promovidos pela Valer, a Universidade Corporativa da Companhia Vale do Rio Doce (atual Vale). O controle sobre a formação dos trabalhadores assume um papel estratégico para a otimização dos resultados organizacionais. Entretanto, demandado pelo mercado, o aumento da oferta de escolaridade para a satisfação das demandas da reestruturação produtiva dista de uma perspectiva de formação omnilateral, sendo marcada, ao contrário, pela lógica do imediatismo e da instrumentalização, além da adesão à cultura organizacional e captura da subjetividade. Sob a ótica das competências necessárias para a execução das tarefas, o trabalho vem se deteriorando e, com ele, o trabalhador. A investigação está referendada no materialismo histórico, que comporta a tarefa de desvendar a realidade fragmentada e articulada com o senso comum. Como instrumento analítico, utilizamos a análise do discurso.

Palavras-chave universidade corporativa; formação profissional; apropriação da subjetividade.
Abstract The purpose of this article is to discuss the concept of education in the professional qualification projects undertaken by the 'Valer,' the Corporate University of the Companhia Vale do Rio Doce (currently Vale). The control over the workers' training takes-on a strategic role that is aimed at optimizing organizational results. However, under market pressure, the increase in the supply of schooling to meet the demands imposed by productive restructuring is far from a perspective of providing omnilateral qualification; rather, it is marked by the logic of immediatism and instrumentalization and adheres to the organizational culture and to capturing subjectivity. From the viewpoint of the competencies that are required to perform the tasks, work has been deteriorating and, with it, the workers. The investigation is endorsed by historical materialism, which bears the task of unveiling the fragmented, articulated reality via common sense. We used the Analysis of Discourse (AD) as an analytical instrument.

Keywords corporate university; professional qualification; appropriation of subjectivity. 


\section{Introdução}

As relações sociais da produção, sob o ideário neoliberal, abrem o caminho para que projetos (con)formativos corporativos se instalem e sejam alardeados como estrada de mão única para o alcance do novo télos ${ }^{3}$ : a vantagem competitiva. O presente texto tem como objetivo apresentar o movimento crescente das iniciativas empresariais voltadas para o sistema educacional, enfocando particularmente um exemplo: a Valer.

As mudanças impulsionadas pelo novo modo de acumulação flexível do capital, o toyotismo, inauguram tempos de adequação e 'voluntária' participação nos projetos 'sugeridos' para a classe trabalhadora. O controle da formação dos trabalhadores assume, no discurso empresarial, um papel estratégico para a otimização da reestruturação produtiva diante do imperativo de excelência mundial, e a Universidade Corporativa (UC), da Companhia Vale do Rio Doce (CVRD), a Valer, surge neste contexto.

Dessa forma, as transformações ocorridas nos últimos 30 anos apontam para o surgimento e conformação do trabalhador-cidadão de novo tipo: dócil e submisso. O movimento de subjugação do trabalhador ao capital extrapola os muros da empresa e alcança a comunidade. Inscrita na lógica toyotista - que sugere falaciosamente a 'autonomia' - a sua subjetividade é dilacerada em prol da mundialização do capital. Do taylorismo-fordismo ao toyotismo emerge um trabalhador comprometido para além do desejo de consumo e de mobilidade social, subsumido emocionalmente ao fantasma do desemprego e da exclusão social, face ao desmonte do Estado Social promovido pelo 'Deus Mercado'.

O Brasil, país de capitalismo periférico, não realizou plenamente o Estado Social característico do capitalismo central no pós-guerra. Contudo, isso não minimiza o fato de que a entrada nos anos 90 foi marcada, aqui, por uma impressionante contemporaneidade com o capitalismo central em relação à diminuição dos rudimentos de Estado Social que havíamos construído.

Com sustentação marcadamente ideológica, as universidades corporativas como novo espaço de formação profissional, reflexo das contradições inerentes ao modo de produção capitalista, buscam diferenciar-se do antigo Departamento de Recursos Humanos (DRH), promovendo a cultura organizacional como a tendência contemporânea, ao mesmo tempo que desqualifica a cultura acadêmica e propõe às instituições de ensino superior, públicas e privadas, a parceria para a certificação dos seus programas educativos. Sob a acepção gramsciana, entendemos que esse tipo de educação, baseada na divisão do trabalho e na alienação do indivíduo, fragmentadora do sentido de pertencimento de classe, vai de encontro à construção do trabalhador, ontologicamente pensado, capaz de 
entender o seu lugar na lógica capitalista e, num embate coletivo, buscar a sua superação.

Apresentaremos a Universidade Corporativa da Companhia Vale do Rio Doce, responsável pela formação de profissionais para as atividades da Vale, e o seu significado para a reprodução do capital e manutenção das 'formas chinesas'4, a partir do sentido polissêmico dos seus discursos, num viés instrumental-utilitarista e mantenedor da perversidade do sistema capitalista.

Este estudo tem a sua relevância fundamentada na escassez de literatura crítica para a importância da compreensão, atualmente necessária, dos princípios educativos nos quais se baseiam esses novos espaços de formação profissional. Abre possibilidades, também, para o debate sobre o sentido da universidade, enquanto legitimadora desses projetos formativos neoliberais.

\section{Estabelecendo limites para a educação profissional}

O cenário da chamada mundialização do capital 5 trouxe consigo mudanças de ordem técnica e organizacional da produção e distribuição da riqueza que apontam para uma crise refletida no achatamento dos salários, no desemprego, na exclusão social e no acirramento da pobreza - conseqüências cruéis da desmobilização das organizações sindicais e da falta de limites característica da concorrência transnacional.

A educação inscrita no rol dos investimentos empresariais se traduz em instrumento de preparação de mão-de-obra e, também, de dominação ideológica. Atentos à cartilha dos organismos internacionais do capital (Comissão Econômica para a América Latina e o Caribe - Cepal; Organização das Nações Unidas para a Educação Ciência e Cultura - Unesco; Fundo Monetário Internacional - FMI; Grupo Banco Mundial - BM; Organização Mundial do Comércio - OMC) (Lima, 2002), os empresários aprofundam a centralidade na educação como geradora de renda e promotora do alívio à pobreza (Leher, 1998). Pensada dessa forma, será o caminho pelo qual os trabalhadores terão capacidade de tomar decisões e flexibilidade suficiente para adaptar-se aos impactos econômicos na era da 'modernização conservadora'.

A inculcação ideológica mascara a realidade e afasta cada vez mais esse trabalhador de uma perspectiva de formação omnilateral, avessa ao imediatismo e à instrumentalização. Sob a ótica das competências necessárias para a execução das tarefas, o trabalho vem se deteriorando e, com ele, o trabalhador. Para Frigotto e Ciavatta (2003, p. 57), “o conceito de educação do homem integrado às forças sociais difere da mera submissão às forças produtivas". 
Para Antunes,

(...) Foram tão intensas as modificações que se pode mesmo afirmar que a classeque-vive-do-trabalho sofreu a mais aguda crise deste século, que atingiu não só a sua materialidade, mas teve profundas repercussões na sua subjetividade e, no íntimo inter-relacionamento destes níveis, afetou a sua forma de ser (Antunes, 1995, p. 23, grifos do autor).

O binômio 'solidariedade-competitividade', utilizado largamente nos discursos hegemônicos, evidencia a exclusão de forma consentida. A figura da flexibilidade reforça a concepção hegemônica de mundo que serve de norteador para as ações políticas relacionadas ao trabalho e ao trabalhador.

Ao relacionar a forma de produção fordista e as condições dos 'altos salários' às quais são submetidos os trabalhadores, exigindo novas qualificações e um dispêndio maior de consumo de força de trabalho consumida, Gramsci alerta para as perspectivas de emancipação do homem a partir da organização do trabalho, desde que este não se constituísse como promotor da degradação humana:

Se o tipo de indústria e de organização do trabalho e da produção própria da Ford é 'racional', pode e deve generalizar-se, ou se, ao contrário, trata-se de um fenômeno 'degenerante' a ser combatido através da força sindical e da legislação (Gramsci, 1988, p. 406-407).

O autor analisa, ainda, as contradições existentes no fordismo, a partir da utilização da técnica e da ciência no desenvolvimento das forças produtivas: ao mesmo tempo que essa nova forma de organização predispõe ao aumento da qualificação do trabalhador e pressupõe um acréscimo do tempo livre, intensificam-se a exploração, a precarização, o desemprego estrutural e o adoecimento no trabalho. Encontramos um modelo de produção calcado na apropriação do saber tácito do trabalhador. Isso ocorre a partir do momento em que esses trabalhadores, chamados a colaborar com o desenvolvimento e crescimento da organização, aderem a esse movimento manipulatório disfarçado sob a chamada responsabilidade social, num momento de precarização do trabalho e dos meios para desenvolvê-lo. O trabalho em equipe, a vedete do toyotismo, acelera a apropriação dos saberes dos trabalhadores e forma o novo trabalhador: coletivo, manipulável e alheio ao produto do seu trabalho.

O estranhamento próprio do toyotismo é aquele dado pelo 'envolvimento cooptado' que possibilita ao capital apropriar-se do saber e do fazer do trabalho. Este, na lógica da integração toyotista, deve pensar e agir para o capital, para a 
produtividade, sob a aparência da eliminação efetiva do fosso existente entre elaboração e execução no processo de trabalho. Aparência porque a concepção efetiva dos produtos, a decisão do que e de como produzir, não pertence aos trabalhadores (Antunes, 1995, p. 42).

O capitalismo, no mundo globalizado, rompe barreiras geográficas, leva o desenvolvimento desigual a toda parte. "Vivem-se formas transitórias de produção, cujos desdobramentos também são agudos, no que diz respeito aos direitos do trabalho. Estes são desregulamentados, são flexibilizados" (Antunes, 1995, p. 24). A apropriação da subjetividade do trabalhador, sob a forma do trabalho desqualificado, repetitivo e intenso, leva ao sofrimento, que se confunde com a possibilidade de melhoria da condição de vida.

Pochmann (2006, p. 113) sinaliza para o dessalariamento a partir da década de 1980, resultante da precarização do trabalho, ao afirmar: “O aumento do desemprego veio acompanhado da diminuta geração de postos de trabalhos, na maioria precária", alterando qualitativamente o mundo do trabalho. Essa alteração contempla, contraditoriamente, maior qualificação do trabalhador em detrimento da qualificação da atividade desempenhada. Esse é um dos determinantes para o surgimento de espaços para a formação permanente de mão-de-obra, para a não permanência da qualidade de vida e do emprego. O aumento da oferta de escolaridade para a satisfação das necessidades oriundas da reestruturação produtiva das empresas não foi suficiente para que o nível de emprego alavancasse. Diante do desemprego estrutural, encontramos um trabalhador empobrecido e um crescimento do setor de serviços combinado com a expansão da economia internacionalizada, que subordinou questões sociais às econômicas. É exatamente nesse cenário de relações desumanizadoras sob o processo de alienação, pautado, principalmente, na pedagogia das competências ${ }^{6}$, que surgiu o novo espaço de (con)formação profissional: a Universidade Corporativa - trazendo controvérsias na sua etimologia, em face do caráter polissêmico que a acompanha.

Ao se utilizar da universidade para os seus propósitos, as empresas 'colam' àquela a sua própria imagem, ao mesmo tempo que a desqualifica. Esse processo de desqualificação procede do desmonte do Estado Social e faz com que a população desvalorize a coisa pública e 'entenda' a iniciativa privada como a promotora das possibilidades de resgate da cidadania e conseqüente melhoria na qualidade de vida. A universidade busca “a preparação dos futuros dirigentes, tanto públicos quanto privados (...) capazes de uma atividade intelectual desinteressada, que buscam não só o êxito material, mas a alegria que se experimenta ao viver um ideal" (Dreze e Debelle, 1983, p. 7) e, portanto, se distingue da função da UC que, sob a lógica neoliberal, pretende desenvolver competências organizacionais nos 
profissionais que atenderão à crescente demanda do mercado. Na contemporaneidade, observamos nas instituições universitárias semelhanças com os centros de formação de executivos demandados pelos ventos da "ideologia da globalização" (Leher, 1998, p. 9). Sendo assim, encontramos uma universidade em crise.

O posicionamento da universidade brasileira diante das políticas de ajuste estrutural contribui, e muito, para a descaracterização da finalidade da instituição. Isto se evidencia na certificação fornecida pela universidade à UC, uma vez que esta não possui autorização oficial para tal. Noutro caso, a universidade operacionaliza os cursos criados pela UC e, ainda, se constitui como parceira nesses projetos.

Lucas e Leher, na sua crítica aos rumos que a educação pública vem tomando, sinaliza que para as elites brasileiras as universidades "não cumprem muito bem o papel de reprodução ideológica (...), teimam em produzir conhecimento quando poderiam contentar-se em propagar o que nos chega pronto e com a etiqueta do primeiro mundo" (Lander apud Lucas e Leher, 2001, p. 257).

A proposta de cunho privatizante do ensino superior formulada durante a década de 1990, e legitimada pela legislação educacional vigente (Brasil, 1998), abre espaço para que as empresas se coloquem como formadoras potenciais de mão-de-obra para o mundo globalizado. Essa prática

polemiza com o sentido do trabalho e a concepção pedagógica da qual se apropriam esses novos espaços para a formação. A educação, como mercadoria, segue negociada, infelizmente, sob o beneplácito do governo.

Não obstante a imposição das agências financeiras internacionais pelo ajuste estrutural, vale ressaltar que o país, sendo uma das maiores economias do mundo, é capaz de capitanear negociações com essas agências. Contudo, internamente existem grupos sociais que compactuam com essa imposição e, portanto, assumem o ideário pari passu.

\section{A universidade corporativa como instrumento de conformação da classe trabalhadora}

Segundo Vergara (2000, p. 181), a UC inspira-se no conceito tradicional7 de universidade que, a partir do ambiente empresarial, pretende desenvolver funcionários, clientes, fornecedores, franqueados, alcançando também a comunidade. Este desenvolvimento objetiva a disseminação de informações, de forma contínua, visando a apropriação, por parte dos funcionários, de habilidades e competências necessárias ao sucesso organizacional no mundo dos negócios, diferentemente daquela, que, como um conjunto de faculdades ou escolas para a especialização profissional e científica, tem por 
função precípua garantir a conservação e o progresso nos diversos ramos do conhecimento, pelo ensino e pela pesquisa. Contudo, elas podem se constituir como parceiras, como no caso da certificação, haja vista que, somente a universidade, devidamente reconhecida e credenciada, pode emitir diplomas e certificados.

Para Éboli (1999, p. 112), o objetivo principal da UC é “o desenvolvimento e a instalação de competências profissionais, técnicas e gerenciais consideradas essenciais para a viabilização das estratégias negociais" a fim de "sustentar a vantagem competitiva, inspirando um aprendizado permanente e um desempenho excepcional dos valores humanos e conseqüentemente da organização" [sic] (Meister, 1999, p. 190).

As UCs são características da nova forma de atuação da área de Recursos Humanos, atualmente voltada para implantação de medidas estratégicas que possam garantir à organização o sucesso no mundo dos negócios. A sistematização dessa nova forma de conhecimento será mediada pelo posicionamento da organização no mercado, retorno social e de capital investido. O e-learning, nessa concepção de educação, apresenta-se de forma inovadora e maximizadora de resultados, posto que, sob um ambiente virtual, as organizações reúnem um significativo número de funcionários para a disseminação de informações, treinamento e adestramento das habilidades. Sob a insegurança promovida pela concorrência e a efemeridade das informações frente aos desafios impostos pela globalização, além da necessidade de manter sob controle aqueles que podem incrementar o processo produtivo, o sistema capitalista cooptou trabalhadores e associações sindicais sob o estímulo da mobilidade e de aumento da melhoria da qualidade de vida.

Segundo Martins (2004), a primeira UC foi criada pela General Eletric, nos EUA, entre 1955 e 1956, para a preparação de executivos, a princípio sugerindo uma maior agilidade e maior aproximação dos programas educativos às exigências produtivas, decorrentes das inovações tecnológicas que, frente ao declínio do modelo taylorista-fordista, culminaram na atual acumulação flexível.

O conceito de UC difundiu-se pelo mundo na década de 1980 e, no Brasil, começa a crescer a partir dos anos 1990. Ainda em Martins (2004, p. 49), no Brasil, empresas públicas e privadas passaram a utilizar a UC como estratégia educacional: Embratel (telecomunicações), Petrobrás (energia), Telemar (telecomunicações), Amil (medicina preventiva), McDonald's (varejo de alimentos), Accor (hotelaria), Brahma (atual Ambev/bebidas), Unimed (medicina preventiva), BankBoston (bancário-financeiro), TV Globo (entretenimento), Empresa Brasileira de Correios e Telégrafos, entre outras.

Dentre as características de uma UC, enfatizamos a composição do quadro docente, formado por professores universitários, executivos e/ou consultores externos, e ainda por profissionais da empresa certificados pela 
instituição de ensino em parceria. Podem ainda formatar os seus próprios programas, ou em parceria com a universidade utilizar os programas desta, dada a sua relevância nacional (Blois e Melca, 2005, p. 39). Segundo o consultor Marcos Vianna, no sítio eletrônico do Instituto MVC,

A falha clamorosa do sistema tradicional de educação e a exigência cada vez maior de aprendizagem contínua obrigam as empresas a adotar uma série de medidas no campo humano de modo a elevar o treinamento e desenvolvimento tradicional a uma categoria mais nobre. (...) a empresa nestes próximos anos deverá transformar-se em um grande pólo de educação, cujo papel é tão importante quanto a sua própria atividade-fim (Vianna, 2005).

Quanto à utilização do termo universidade, Herbert Martins informa que não se confunde com a conceituação histórica de universidade:

(...) é um empréstimo que, obviamente, tem um apelo mercadológico podendo vir a ter um uso marqueteiro ou não, mas que também é capaz de conduzir a uma interessante idéia de ensino e pesquisa, levando a essência do conceito de universidade para outros espaços sociais, que não somente os limites do campus universitário (Martins, 2004, p. 57).

Em agosto de 2004, foi criada a Associação Brasileira de Educação Corporativa, que busca a obtenção do direito de certificação sem a interferência do Estado.

A urgência da necessidade de um trabalhador de qualificação dirigida a essas exigências produtivas é o ingrediente para a formação da 'sociedade do conhecimento'.

Na chamada 'Sociedade do Conhecimento', os sujeitos sociais deixam de ser as classes fundamentais, como na teoria gramsciana e em toda a tradição do Materialismo Histórico, sendo essa condição atribuída às tecnologias (Santos, 2001, p. 34).

Ao desqualificar o Estado, nas suas funções educativas, as organizações tomam para si a tarefa de educadora contemporânea, alardeando até, sob aspectos reducionistas, o lugar da universidade.

Considerando-se que o télos contemporâneo - a vantagem competitiva - entre organizações e os sujeitos - para esses como determinantes para a empregabilidade 8 - é freqüente no receituário neoliberal para a 'classe-quevive-do-trabalho' (Antunes, 1999), apoiamo-nos no materialismo históricodialético, que comporta a tarefa no sentido de desvendar essa realidade fragmentada e articulada com o senso comum, capaz de ressemantizar 
conceitos teóricos caros aos defensores da sociedade civil, na concepção gramsciana. Nesse sentido, as parcelas trabalhadoras podem, a partir da vontade coletiva, transformar a realidade com vistas à construção de uma nova hegemonia.

Como instrumento analítico, utilizaremos as contribuições de Mikhail Bakhtin e Eni Orlandi para a análise do discurso, a fim de captarmos os elementos sócio-histórico-ideológicos presentes na linguagem constituída hegemonicamente, uma vez que "o mundo da pseudoconcreticidade é um claro-escuro de verdade e engano. O seu elemento próprio é o duplo sentido" (Kosik, 1976, p.11), e o método marxista é o esforço para se dissecar a realidade fetichizada, encontrada no discurso da ideologia dominante. Para Orlandi (2003, p. 48), "pela interpelação ideológica do indivíduo em sujeito inaugura-se a discursividade". Sendo assim, a análise do discurso permite a busca pelo sentido produzido pelo simbólico, uma vez que é necessário identificar as condições nas quais ele foi produzido, considerando-se que a linguagem não é transparente. A materialidade do discurso se desvendará à medida que for considerada a interação social.

Utilizaremos trechos dos relatórios anuais de 2003 a 2006 e da revista Atitude, publicação dirigida ao público interno e externo da Vale, disponibilizados eletronicamente pela empresa. A representatividade do corpus selecionado permitirá que utilizemos os procedimentos sugeridos pela análise do discurso: a busca do(s) sentido(s) a partir da sua historicidade e dimensão política.

Segundo informações do relatório anual 2005, a Vale ${ }^{9}$ está presente em 14 estados brasileiros e em cinco continentes. Essa organização extrai, transforma, produz, transporta e exporta produtos. A Vale surge para viabilizar o 'Acordo de Washington', celebrado entre os Estados Unidos, a Inglaterra e o Brasil em 1942, como finalidade 'preventiva' à escassez de matérias-primas para a indústria bélica, no contexto da Segunda Guerra Mundial.

Desde a implantação da CVRD, na década de 1940, na cidade de Itabira, no interior de Minas Gerais, ocorre uma intensa transformação local, em face do progresso que se aproximava. Entretanto, à chegada da CVRD se impõe um modo de produção insalubre e penoso. O processo de formação dos operários é operado sob condições adversas: o ritmo da produção é acionado pela força humana, num ambiente competitivo e de vigilância. Uma vigilância que ultrapassa os muros da empresa, chega às famílias e toma conta da cidade, num processo de apropriação subjetiva sob o olhar assistencialista do Estado. Àquela época, sob a iniciativa do Ministério do Trabalho, formaliza-se a organização sindical dos trabalhadores. A legislação trabalhista, cujo objetivo era "defender os interesses econômicos, jurídicos, higiênicos e culturais dos trabalhadores", na realidade, regulava os sindicatos, que tinham como função reorientar as relações entre capital e 
trabalho e, principalmente, controlar quaisquer possibilidades de manifestação ou de resistência dos trabalhadores (Minayo, 2004).

De caráter transnacional, da era da mecanização (década de 1970) à reestruturação produtiva de ordem mundial, a sua história se confunde com a formação da classe trabalhadora brasileira, num momento de definição de políticas nacionais sob a aura do nacional-desenvolvimentismo. Hoje, em tempos de acumulação flexível, premida pelo avanço das novas tecnologias e exigências para a consolidação internacional, a implementação da UC possibilita a avaliação e desenvolvimento das competências necessárias aos rumos dos negócios.

Primeira empresa a ser privatizada na década de 1990, destaca a responsabilidade sócio-ambiental como fundamental para o planejamento estratégico, na busca pelo posicionamento global, diversificação dos seus produtos e retorno de valor aos seus acionistas.

Todas as iniciativas educacionais apresentadas se apóiam na chamada responsabilidade sócio-ambiental, que compreendem ações voltadas para a melhoria da qualidade de vida dos trabalhadores e das suas comunidades, particularmente aquelas onde a Vale está inserida:

O compromisso com as PESSOAS acompanha a Vale desde as suas origens, está presente no seu processo de internacionalização e vem ajudando a mudar a realidade social das regiões onde está inserida, fomentando a criação de condições para o desenvolvimento sustentável Como em qualquer relacionamento, o comprometimento das PESSOAS da Vale com as PESSOAS das comunidades pressupõe um aprendizado constante e conjunto. A Vale respeita os valores das localidades onde atua, no Brasil e no exterior, e se empenha para que sua trajetória de crescimento promova o desenvolvimento econômico e social, gerando emprego, renda e melhoria na qualidade de vida da população (CVRD, 2005, p. 57, grifos do autor).

Se retomarmos a questão da origem da Vale e as suas relações com a cidade de Itabira, por ocasião da sua chegada àquela localidade, em 1942, evidenciaremos a relação simbiótica anteriormente sinalizada. Na fala de um dos seus primeiros trabalhadores, extraída do livro de Maria Cecília Minayo, De ferro e flexíveis, configura-se essa simbiose derivada da apropriação do lugar por uma atividade econômica dominante, uma vez que a cidade passa a 'viver' em função da empresa: "ai de Itabira se não fosse a Vale!, ai da Vale se não fosse Itabira!" (Minayo, 2004, p. 54). Minayo aponta, ainda, elementos contraditórios nessa relação de amor e ódio, pois a chegada da Vale, nesse espaço urbano já constituído com vida econômica, social, cultural e religiosa cria conflito de interesses com os cidadãos. Entretanto, no mesmo momento em que a intensificação industrial adere à reestruturação produtiva de ordem mundial, mostra de que maneira a Vale 
utiliza como máscara a face paternalista do Estado e promove a cidade de Itabira a um ponto esquecido nas estatísticas da empresa. Confundem-se trabalhador e empresa.

Isso posto, o compromisso com as pessoas 'desde as suas origens' contrasta com o enunciado. Quem enuncia 'se esquece' da memória social, mesmo que a Vale seja considerada por muitos dos seus trabalhadores, ainda hoje, como a melhor senão a única melhor instituição para se empregar. E as revistas-partido não desmentem a história.

A Vale enfatiza as ações sociais desenvolvidas junto às comunidades onde estão inseridas as suas unidades operacionais. "A inserção na comunidade pressupõe o entendimento de que a Companhia é parte desta comunidade" (CVRD, 2005, p. 58). A Fundação Vale do Rio Doce, o braço social da Vale, é a responsável pelo desenvolvimento e implementação destas atividades, que abrangem ações nas áreas de educação, saúde e economia local, voltadas para o chamado 'desenvolvimento sustentável'. "Por meio da Fundação Vale do Rio Doce, a Companhia investe em programas sociais estruturantes, focados nas áreas de Educação, Cultura e Economia Local (...) em parceria com ONGS, sociedade civil organizada e o poder público" (CVRD, 2005, p. 60).

A abrangência dos programas desenvolvidos pela Vale encontra respaldo nos diversos segmentos da sociedade. A emergência das organizações não governamentais - termo dotado de polissemia utilizado para ações que visam preencher as lacunas deixadas pelo Estado e mercado, e, nos últimos anos, vem assumindo um caráter desprendido da intenção filantrópica, para se constituir como partido, na acepção gramsciana - permite um deslocamento do caráter neoliberalizante das atividades sociais, uma vez que corrigirá as mazelas causadas pela ingerência do Estado, apesar de historicamente produzidas e perversamente omitidas do conhecimento público via midiática e educacional, para uma nova forma de movimento social. Devese considerar que essas instituições se alimentam de fontes de financiamento internacionais e da iniciativa privada, via fundações.

Esta sociedade civil, no trecho citado, se organiza mediada por interesses ideologicamente dominantes e pela vulgarização semântica, já que se assenta sob bases não-éticas e distantes da luta de classes. Ao destacar o poder público, indissociando-o da sociedade civil, o trecho vai de encontro ao entendimento de que "a sociedade civil é o momento organizativo a mediar as relações de produção e a organização do Estado, produzindo organização e convencimento" (Fontes, 2006, p. 212).

A Vale possui mais de 38 mil empregados, representados por 52 sindicatos. Realiza programas de capacitação profissional a partir de parcerias com instituições de ensino, dentro e fora do país, com o propósito de atender às suas necessidades. 
A qualidade da educação influencia tanto na elevação da renda das populações, por meio do crescimento da produtividade, da empregabilidade e do empreendedorismo quanto no aumento da sua qualidade de vida, pela aplicação, melhor dos recursos familiares, reduzindo o grau de pobreza futuro (CVRD, 2005, p. 60).

\section{E Leher sinaliza:}

a inscrição da educação nas políticas de aliviamento da pobreza como ideologia capaz de evitar a 'explosão' dos países e das regiões periféricas e de prover o neoliberalismo de um porvir em que exista a possibilidade de algum tipo de e inclusão ('todo aquele que se qualificar poderá disputar, com chance, um emprego') (Leher, 1998, p. 9).

A cultura do voluntariado é permanentemente estimulada entre os empregados, contratados e seus familiares; e, para isso, utiliza a metodologia dos Círculos de Controle de Qualidade (CCQ)10. O sítio eletrônico do Programa de Voluntários Vale anuncia,

Assumir e difundir o conceito de voluntariado como uma atividade espontânea, em que as pessoas doam seu tempo, trabalho e talento para apoiar indivíduos, comunidades e causas, sem interesse (...) incentivando que a ação comunitária dos empregados, contratados e seus familiares contribua com o desenvolvimento territorial sustentável das comunidades em que o grupo CVRD atua. (Voluntários Vale, 2005).

O trecho corrobora com o discurso vigente de que o Estado é incapaz de assumir as suas responsabilidades e as transfere para a sociedade e, sob o mote da responsabilidade social, busca a adesão da classe trabalhadora a esse movimento.

Segundo o relatório, a Vale realiza, periodicamente, ações educativas com o tema "Segurança e Saúde Ocupacional" para fortalecer a importância da preservação da vida, embora reconheça que os acidentes continuem acontecendo.

Através da Valer, a sua UC, os empregados têm acesso às ações educacionais que visam o aumento da sua autonomia e capacidade produtiva (CVRD, 2005, p. 84), com o objetivo de impulsionar o crescimento da companhia. Além de empregados e acionistas, a Vale se relaciona com o governo, entidades do chamado Terceiro Setor, sindicatos, imprensa, associações e demais setores da sociedade civil organizada. A Valer foi fundada em 2003 para "preparar os empregados para as suas atividades específicas e também 
para os novos desafios da empresa, que vive um processo de crescimento acelerado no mercado global" (CVRD, Relatório Social, 2003, p. 3) e oferece cursos presenciais e à distância. Para a Valer,

Investir na disseminação de conhecimento é a diretriz em vários projetos de Recursos Humanos da CVRD (...) a Valer busca vincular a educação ao desenvolvimento estratégico e às metas da empresa. A principal delas é estar entre as três maiores companhias mineradoras diversificadas do mundo nos próximos seis anos. Pois difundir conhecimento e alinhar pessoas e visão de negócios é uma das melhores maneiras de se chegar lá (Revista Atitude, 2003, p. 25).

Para essa organização, "os empregados são fundamentais em sua estratégia de crescimento" (CVRD, Relatório Social, 2003, p. 3) e a implementação dessa estratégia educacional sugere a validação dessa assertiva. A partir dessa iniciativa, ela poderá mapear e controlar todas as competências individuais necessárias às suas estratégias organizacionais. Esta visão para a excelência mundial parte do planejamento estratégico das empresas que se colocam sob o télos da vantagem competitiva. Após a compra de uma empresa de origem canadense, a Inco Limited, produtora de níquel, acaba de alçar o posto de segunda maior mineradora do mundo, em valores de capital (CVRD, 2006), legitimando a chamada mundialização do capital. Entretanto, os custos humanos e sociais para o alcance desta posição permanecem questionáveis, particularmente sob o aspecto ético-político dos projetos educacionais por ela implementados.

(...) a Valer lançou o ciclo de avaliação de competências. Por ele, todos os empregados analisam seu perfil profissional e, em seguida, são avaliados pelos superiores. A partir daí, cada um vai elaborar seu plano de desenvolvimento e, conseqüentemente, contribuir para elevar o valor do capital humano na empresa. É um caminho para conhecer melhor seus empregados e alcançar as competências necessárias aos objetivos do negócio (CVRD, 2003, p. 25).

Em linhas gerais, o caminho a ser trilhado pelo empregado é o caminho norteado pela estratégia empresarial.

A Vale investe em programa de aperfeiçoamento que combina reflexão individual com planejamento de metas para aproveitar melhor os talentos da empresa (...) os Ritos de Passagem, promovidos pelo Centro de Gestão e Liderança da Universidade Corporativa Vale, a Valer. A idéia do encontro era promover o autoconhecimento dos líderes e, assim, estimular cada um a utilizar da melhor forma o próprio potencial (Revista Atitude, 2006, p. 39). 
Para Motta (1986), esse processo implica a ruptura de padrões de comportamentos ligados à sua origem social e, também, a mudança de valores e auto-imagem.

Verificamos que a autonomia dos empregados em relação aos rumos da sua carreira vai ao encontro da empregabilidade. Transferida a responsabilidade, mesmo que ele possa ter traçado o caminho, será dele a decisão final? Para a empresa, o conceito de autodesenvolvimento do empregado já está predeterminado, por mais paradoxal que isso possa parecer. A apropriação da subjetividade do trabalhador é operada de tal forma que o conformismo é certo.

De acordo com Scliar (1997), “a expressão 'rito de passagem' foi cunhada por Arnold van Gennep, em 1909, para descrever o processo pelo qual o indivíduo, ao mover-se de uma situação social para outra, recebe aceitação e reconhecimento", ou seja, sob a ótica neoliberal, este indivíduo se desfaz da sua individualidade e se transforma em um novo ser, um indivíduocorporativo, adesista daqueles valores e costumes pautados pela missão da empresa.

Dessa forma, um 'pseudopoder' se instala nas relações sociais construídas pelo capital, que utiliza mecanismos de dominação a partir de uma relação aparentemente livre em que dominação e subordinação 'desaparecem'. Quanto maior a liberdade, maior a disciplina voluntária e adesista por parte da classe trabalhadora, mesmo que oprimida. Da subsunção formal à subsunção real do trabalho sob o capital, transformam-se o modo de acumulação e as relações entre os envolvidos no processo produtivo. Eis o momento econômico-corporativo, onde o trabalhador personifica as relações mercantilistas, tornando-se um trabalhador de novo tipo: preposto do modo de produção capitalista. No rito de passagem se explicita a relação fetichizada, característica do claro-escuro do poder concedido aos indivíduos, dentro de um clima de equidade tecnicamente produzida e politicamente nula.

Mais complexificada, a aparência de maior liberdade no espaço produtivo tem como contrapartida o fato de que as personificações do trabalho devem se converter ainda mais em personificações do capital. Se assim não o fizerem, se não demonstrarem essas 'aptidões', ('vontade', 'disposição' e 'desejo'), trabalhadores serão substituídos por outros que demonstrem 'perfil' e 'atributos' para aceitar esses 'novos desafios' (Antunes, 1999, p. 130).

Esse tipo de organização se apropria de tal forma do indivíduo que o destitui de consciência e o constitui no 'estranhamento'. O formato ideológico do discurso da Valer induz os seus trabalhadores a 'vestir a camisa', reflexo da mudança de mentalidade advinda do processo de modernização das relações de produção da empresa. Uma nova mentalidade é requerida 
para os tempos atuais, em que as relações sociais transitarão entre a ética no trabalho, a solidariedade e os ideais organizacionais. Uma nova identidade manifestamente corporativa, tão 'interessada', na acepção gramsciana, quanto aos objetivos da empresa que a criam e fomentam a sua reprodução. Eis o êxito do processo de inculcação ideológica e aculturação. Para Antunes (1999, p. 133), "nos pólos mais intelectualizados da classe trabalhadora, que exercem seu trabalho intelectual abstrato, as formas de reificação têm uma concretude particularizada, mais complexificada (mais 'humanizada' em sua essência desumanizadora)" (Antunes, 1999, p. 133).

Quando a Vale anuncia:

[que] o Programa de Formação Profissional da CVRD capacita jovens que concluíram o ensino médio ou técnico, oferecendo formação específica em manutenção e operação nas suas áreas de negócios [e que] o objetivo é formar profissionais em áreas nas quais a oferta do mercado de trabalho é pequena ou inexistente (CVRD, 2004, p. 67).

A ênfase no treinamento e na educação profissionalizante revela a nãointencionalidade de estimular o trabalhador ao ensino superior, uma vez que as competências técnicas desenvolvidas nessa UC são tão específicas que determinada ocupação só será encontrada na própria empresa. Isso vai ao encontro das trilhas de desenvolvimento que 'auxiliam' o profissional a planejar a sua carreira e, ao mesmo tempo, lhe diz: "Só vale ir até aí!"

\section{À guisa de conclusão}

Naquilo que Gramsci acredita como elevação cultural, o movimento das competências impõe-se como a fórmula para a melhoria da qualidade de vida do trabalhador e da sua família. Como 'tentáculos do monstro' (Minayo, 2004), a ideologia da carreira, aliada à ideologia da cidadania, abre espaço para a expansão dos projetos educacionais à moda do guarda-chuva estratégico de Meister. O homem que se constitui ética e politicamente a partir do seu trabalho cede, forçosamente, o lugar ao homem individualista e competitivo, embalado por um a-historicismo que o deixa refém da 'mão invisível' do mercado, e o impede de se formar um homem livre e capaz técnica e cientificamente. O trabalho se torna cada vez mais simples e, aliado às novas tecnologias, não permite que a sociedade se construa dentro de uma concepção integradora e emancipatória. O movimento no sentido de formar o consenso esconde processos antidemocráticos e inviabilizadores da luta social, embora se 'vendam' como sociais. 
Sob os auspícios do toyotismo que adestra, disciplinariza, expropria e aliena, o poder hegemônico do capital promove a destruição da cultura operária em favor da cultura delineada pelos valores da opressão e da submissão, em que a comunidade é levada a privilegiar a cidadania que se constitui a partir das relações com a Vale: a cidadania corporativa. Indo além dos contornos da UC, a Vale se propõe como a educadora de novo tipo, não somente para os seus profissionais, mas também para o país, à sua imagem e semelhança. No universo da educação corporativa contribui para a ressignificação do caminho para a disciplinarização do 'cidadão que vale'.

Dessa maneira, outros projetos de educação caminham para a universalização da Vale, sob a faceta de ações sociais que, ancoradas na responsabilidade sócio-ambiental, delineiam 'o perfil válido' para o télos da vantagem competitiva, na medida em que orienta espaços educativos com vistas à excelência mundial. A 'empresa privada que mais investe no Brasil' segue universalizando a exclusão e conta com o 'apoio' da comunidade para o seu êxito.

Santos (2004, p. 50), numa análise cuidadosa, sinaliza que o impacto causado pelas "novas tecnologias de informação e comunicação na proliferação das fontes de informação e nas possibilidades de ensino-aprendizagem a distância" também corrobora para essa crise e enfatiza a urgente necessidade de um projeto de universidade em face da confrontação com esse novo tipo de produção de conhecimento que, para além de acirrar a desigualdade e exclusão social, afeta a pesquisa, a formação e a extensão universitária.

Diante disso, num cenário de ofertas de formação educacional de 'todos os tipos' e de produção de intelectuais que, segundo Gramsci (2004, p. 53), "contribuem para manter ou para modificar uma concepção do mundo", se faz mais do que urgente redescobrir as possibilidades de superação do estado de coisas capitaneado pela divisão do trabalho no seu momento mais perverso. Se a educação foi rebaixada à condição de mercadoria, sob a complacência do Estado, devemos nos lembrar de que "as circunstâncias são modificadas precisamente pelos homens e que o próprio educador precisa ser educado" (Marx, 1972, p. 208-209).

À medida que a classe dominante se coloca como a educadora contemporânea, orientada pela mundialização do capital e exigindo profissionais formatados para esse fim, este trabalho buscará contribuir para o debate teórico sobre o sentido da universidade enquanto legitimadora dos projetos formativos neoliberais, já que, de acordo com Mészáros (2006, p. 272), "nenhuma pessoa em sã consciência negaria que a educação está, hoje, em crise". 


\section{Notas}

1 Professora do Centro Universitário Plínio Leite (Unipli), Niterói, Rio de Janeiro, Brasil. Mestre em Ensino em Biociências e Saúde pelo Instituto Oswaldo Cruz, da Fundação Oswaldo Cruz (IOC/Fiocruz). < giovane.ramos@gmail.com>

Correspondência: Rua Visconde do Uruguai, 208, apto. 704, Centro, Niterói, Rio de Janeiro, CEP 24.030-072.

2 Pesquisadora da Escola Politécnica de Saúde Joaquim Venâncio, da Fundação Oswaldo Cruz (EPSJV/Fiocruz). Doutora em Educação pela Universidade Federal do Rio de Janeiro (UFRJ).<apsantos@fiocruz.br>

3 "O télos é uma imagem construída pelo discurso hegemônico com o objetivo de se tornar uma meta a ser incansavelmente perseguida pelo conjunto da sociedade, sob a direção da fração de classe que a elaborou, no caso, a burguesia industrial. A existência discursiva desse télos acaba por justificar, no presente, todas as privações e todos os sacrifícios (coletivos e individuais) impostos à classe trabalhadora pela implementação das políticas que, proclamadamente, encaminharão a sociedade ao fim/télos projetado" (Rodrigues, 2005, p. 251).

${ }^{4}$ Gramsci sinaliza a possibilidade de uma escola formativa-cultural, não imediatamente interessada e para além das formas chinesas que, segundo o autor, tende a perpetuar as diferenças tradicionais, ou seja, a ideologia da classe dominante, a exemplo das reformas do sistema escolar e educacional ocorridas na Itália fascista, em 1923. Na escola atual, em função da crise profunda da tradição cultural e da concepção da vida e do homem, verifica-se um processo de progressiva degenerescência: "as escolas de tipo profissional, isto é, preocupadas em satisfazer interesses práticos imediatos, predominam sobre a escola formativa, imediatamente desinteressada. $\mathrm{O}$ aspecto mais paradoxal reside em que este novo tipo de escola aparece e é louvado como democrático, quando, na realidade, não só é destinado a perpetuar as diferenças sociais, como ainda a cristalizá-las em formas chinesas" (Gramsci, 2004, p. 49).

5 “(...) garantir a apropriação, em condições tão regulares e seguras quanto possível, das rendas financeiras - juros e dividendos - numa escala mundial" (Chesnais apud Cardoso, 2006, p. 43).

${ }^{6}$ As competências são as modalidades estruturais da inteligência, ou melhor, ações e operações que utilizamos para estabelecer relações com e entre objetos, situações, fenômenos e pessoas que desejamos conhecer. As habilidades decorrem das competências adquiridas e referem-se ao plano imediato do 'saber fazer' (Brasil. MEC. Enem, 2000) [grifos nossos]. (...) a competência "é uma noção oriunda do discurso empresarial (...) marcada política e ideologicamente por sua origem e da qual está totalmente ausente a idéia de relação social, que define o conceito de qualificação para alguns autores" (Hirata, 1994, p. 128).

${ }^{7}$ A expressão 'tradicional', aqui utilizada, refere-se, sob reducionismos, à finalidade da universidade.

8 No discurso neoliberal, o termo sugere a capacidade do trabalhador para obter o emprego e manter-se nele, sob as exigências do mercado de trabalho. 
9 Durante este trabalho privilegiamos a pesquisa realizada por Maria Cecília de Souza Minayo, que narra a saga dos mineiros de Itabira e suas relações com a CVRD, da implantação no país até o processo de reestruturação produtiva, no livro de sua autoria De ferro e flexiveis.

10 "Os Círculos de Controle de Qualidade constituem um subsistema da Gestão pela Qualidade Total, e têm os seguintes objetivos, do ponto de vista empresarial: (a) propiciar crescimento das pessoas, estimulando a máxima utilização do seu potencial; (b) respeitar a natureza humana e gerar um ambiente onde haja satisfação no trabalho; (c) contribuir para o fortalecimento da organização e desenvolvimento da sociedade; (d) reduzir custos, promover melhoria da produtividade. Seus princípios são: autodesenvolvimento; desenvolvimento mútuo; participação voluntária; atividades em grupo; participação de todos; uso de métodos e técnicas; criação de raízes; ativação e permanência das atividades; criatividade; consciência da qualidade, de problemas e de melhoramento. A filosofia e o método do CCQ foram apresentados pela primeira vez no Japão, em julho de 1950, visando estender o conceito de qualidade à produção. No Brasil, o CCQ chegou em 1971, sendo utilizado em primeiro lugar pela Johnson \& Johnson, Volkswagen e Embraer" (Minayo, 2004, p. 324).

\section{Referências}

ANTUNES, Ricardo. Adeus ao trabalho?: ensaio sobre as metamorfoses e a centralidade do mundo do trabalho. São Paulo: Cortez, 1995.

BAKHTIN, Mikhail. Marxismo e filosofia de linguagem. São Paulo: Hucitec, 1997.

BLOIS, Marlene; MELCA, Fátima. Educação corporativa: novas tecnologias na gestão do conhecimento. Rio de Janeiro: Consultor, 2005.

BRASIL. Lei $\mathrm{n}^{\circ}$ 9.394, de 24 de dezembro de 1996. Estabelece as Diretrizes e Bases da Educação Nacional. Educação Profissional: Legislação básica. 2. ed. Brasília: Proep. 1998.

CARDOSO, Miriam Limoeiro. Sobre as relações sociais capitalistas. In: NEVES, Lúcia M. W.; LIMA, Júlio César F. (Orgs.). Fundamentos da educação escolar do Brasil contem- porâneo. Rio de Janeiro: Editora Fiocruz, 2006.

COMPANHIA VALE DO RIO DOCE (CVRD). Relatórios anuais: 2003; 2005; 2006. Disponível em: <www.cvrd.com.br $>$. Acesso em: 3 mar. 2006.

DREZE J., DEBELLE J. Concepções da universidade. Tradução de Francisco de Assis Garcia e Celina Fontenele Garcia. Fortaleza: Universidade Federal do Ceará, 1983.

EBOLI, Marisa. Desenvolvimento e alinhamento dos talentos humanos às estratégias empresariais: o surgimento das universidades corporativas. São Paulo: Schmukler, 1999.

FONTES, Virginia. A sociedade civil no Brasil contemporâneo: lutas sociais e luta teórica na década de 1980. In: NEVES, Lúcia M. W.; LIMA, Júlio César F. (Orgs.). 
Fundamentos da educação escolar do Brasil contemporâneo. Rio de Janeiro: Editora Fiocruz, 2006.

FRIGOTTO, Gaudêncio; CIAVATTA, Maria. Pensar e fazer no campo educativo: relações de poder e racionalidades em jogo. OEI. Educación e política. La educación como acción coletiva. Buenos Aires: OEI/Fondo de Cultura Econômica. No prelo.

Educar o trabalhador produtivo ou o ser humano emancipado? Trabalho, Educação e Saúde, v. 1, n. 1, p. 45-60. Rio de Janeiro: Escola Politécnica de Saúde Joaquim Venâncio, Fundação Oswaldo Cruz, 2003.

GRAMSCI, Antonio. Maquiavel, a politica e o Estado moderno. Rio de Janeiro: Civilização Brasileira. 1988

Cadernos do cárcere. Tradução Carlos Nelson Coutinho. Rio de Janeiro: Civilização Brasileira, 2004, v. 2.

HIRATA, Helena. Da polarização das qualificações ao modelo da competência. In: FERRETTI, Celso et al. Novas tecnologias, trabalho e educação. Petrópolis: Vozes. 1994.

KOSIK, Karel. Dialética do concreto. Rio de Janeiro: Paz e Terra, 1976.

LEHER, Roberto. Da ideologia do desenvolvimento à ideologia da globalização: a educação como estratégia do Banco Mundial para 'alívio' da pobreza. Tese de doutorado, São Paulo: Faculdade de Educação, Universidade de São Paulo,1998.

LIMA, Katia S. Organismos internacionais: o capital em busca de novos campos de exploração, In: NEVES, Lúcia M. W. (Org.). O empresariamento da educação: novos contornos do ensino superior no Brasil dos anos 1990. São Paulo: Xamã, 2002.

LUCAS, Luiz Carlos G.; LEHER, Roberto. Aonde vai a educação pública brasileira? Educação e Sociedade. Campinas, v. 22, n.
77, 2001. Disponível em: <www.scielo.br/ scielo.php?script $=$ sci_arttext $\&$ pid $=$ S01017 $3302001000400012 \& \operatorname{lng}=$ pt $\& n r m=i s s o>$. Acesso em: 7 out. 2006.

MARTINS, Hebert Gomes. Estudo da trajetória das universidades corporativas no Brasil. Tese de doutorado, Rio de Janeiro: Coppe/Universidade Federal do Rio de Janeiro, 2004.

MARX, Karl. Teses sobre Feuerbach. In: Marx, Karl; Engels, Friedrich. Obras escolhidas. São Paulo: Alfa Omega, 1972, v. 3, p. 208-209.

MEISTER, Jeanne. C. Educação corporativa: a gestão do capital intelectual através das universidades corporativas. São Paulo: Makron Books, 1999.

MÉSZAROS, István. A teoria da alienação em Marx. São Paulo: Boitempo, 2006.

MINAYO, Maria Cecília de Souza. De ferro e flexiveis: marcas do Estado-empresário e da privatização na subjetividade operária. Rio de Janeiro: Garamond, 2004.

MOTTA, Fernando Claúdio Prestes. Organização e poder: empresa, Estado e escola. São Paulo: Atlas, 1986

ORLANDI, Eni. Análise de discurso: princípios e procedimentos. Campinas: Pontes, 2003.

POCHMANN, Marcio. Economia brasileira hoje. In: NEVES, Lúcia M. W.; LIMA, Júlio César F. (Orgs.). Fundamentos da educação escolar do Brasil contemporâneo. Rio de Janeiro: Editora Fiocruz, 2006.

REVISTA ATITUDE. Companhia Vale Rio Doce. Rio de Janeiro, 2003; 2006. Quadrimestral.

RODRIGUES, José. A nova educação superior brasileira no padrão de acumulação flexível. In: QUARTIERO, Elisa Maria; BIANCHETTI, Lucidio (Orgs). Educação cor- 
porativa. Mundo do trabalho e do conhecimento: aproximações. Santa Cruz do Sul: Edunisc, 2005

SANTOS, Aparecida Fátima Tiradentes. A escola como cortina de fumaça: trabalho e educação no 'novo ensino médio'. Tese de doutorado, Rio de Janeiro: Faculdade de Educação, Universidade Federal do Rio de Janeiro, 2001.

SANTOS, Boaventura de Sousa. A universidade no século XXI: para uma reforma democrática e emancipatória da universidade. São Paulo: Cortez, 2004.

SCLIAR, Moacir. O exame pré-nupcial: um rito de passagem da saúde pública. Cadernos de Saúde Pública. [on line]. Disponível em: $<$ www.scielo.br/pdf/csp/v13n3/0177.pdf >. Acesso em: 27 out. 2006.
VERGARA, Silvia Constant. UC: a parceria possível entre empresa e universidade tradicional. Cadernos Ebap, n. 111. Rio de Janeiro: Fundação Getulio Vargas, nov. 2000.

VIANNA, Marcos Aurélio F. UC: Não só universidade, não só corporativa, 2005. Disponível em: <www.aprenderonline.com.br/ ver_noticia.php? codigo $=94>$. Acesso em: 3 mai. 2005.

VOLUNTÁRIOS VALE. Política de Voluntariado - Seus objetivos e seus princípios. 2005. Disponível em <www.voluntarios vale.org.br/site/pagina.php?idconteudo $=14$ 9>. Acesso em: 03 mar. 2006.

Recebido em 24/05/2008

Aprovado em 26/06/2008 